\title{
CONSORT for Reporting Randomized Controlled Trials in Journal and Conference Abstracts: Explanation and Elaboration
}

\author{
Sally Hopewell ${ }^{1,2 *}$, Mike Clarke ${ }^{1,3}$, David Moher ${ }^{4,5}$, Elizabeth Wager ${ }^{6}$, Philippa Middleton ${ }^{7}$, Douglas G. Altman ${ }^{2}$, \\ Kenneth F. Schulz ${ }^{8}$, and the CONSORT Group
}

1 UK Cochrane Centre, Oxford, United Kingdom, 2 Centre for Statistics in Medicine, Wolfson College, Oxford University, Oxford, United Kingdom, 3 School of Nursing and Midwifery, Trinity College Dublin, Dublin, Ireland, 4 Chalmers Research Group, Children's Hospital of Eastern Ontario Research Institute, Ottawa, Canada $\mathbf{5}$ Department of Epidemiology and Community Medicine, Faculty of Medicine, University of Ottawa, Ottawa, Canada, 6 Sideview, Princes Risborough, United Kingdom, 7 Discipline of Obstetrics and Gynaecology, The University of Adelaide, Adelaide, Australia, 8 Family Health International, Research Triangle Park, North Carolina, United States of America

Funding: Financial support was provided by the following sources to convene a meeting of the CONSORT Group in Montebello, Canada, in January 2007: the American Society of Clinical Oncology, BMJ, Canadian Institutes for Health Research,

Johnson \& Johnson, The Lancet, Nordic Cochrane Centre, PLoS

Medicine, UK Cochrane Centre, and UK National Co-ordinating Centre for Research Methodology. DM is supported by a University of Ottawa Research Chair.

Competing Interests: All authors are involved in many initiatives in health care and healthcare research which should benefit from a wide uptake of the CONSORT for Abstracts statement.

Academic Editor: Erik von Elm, University of Bern, Switzerland

Citation: Hopewell S, Clarke M, Moher D, Wager E, Middleton $\mathrm{P}$, et al. (2008) CONSORT for Reporting Randomized Controlled Trials in Journal and Conference Abstracts: Explanation and Elaboration. PLoS Med 5(1): e20. doi:10.1371/journal. pmed.0050020

Received: October 3, 2007 Accepted: December 7, 2007 Published: January 22, 2008

Copyright: (c) 2008 Hopewell et al This is an open-access article distributed under the terms of the Creative Commons Attribution License, which permits unrestricted use, distribution, and reproduction in any medium, provided the original author and source are credited.

Abbreviations: CONSORT Consolidated Standards of Reporting Trials; CSE, Council of Science Editors; ICMJE, International Committee of Medical Journal Editors; STARD, Standards for Reporting Diagnostic Accuracy; WAME, World Association of Medical Editors

* To whom correspondence should be addressed. E-mail: shopewell@ cochrane.co.uk

\section{A B S T R A C T}

\section{Background}

Clear, transparent, and sufficiently detailed abstracts of conferences and journal articles related to randomized controlled trials (RCTs) are important, because readers often base their assessment of a trial solely on information in the abstract. Here, we extend the CONSORT (Consolidated Standards of Reporting Trials) Statement to develop a minimum list of essential items, which authors should consider when reporting the results of a RCT in any journal or conference abstract.

\section{Methods and Findings}

We generated a list of items from existing quality assessment tools and empirical evidence. A three-round, modified-Delphi process was used to select items. In all, 109 participants were invited to participate in an electronic survey; the response rate was $61 \%$. Survey results were presented at a meeting of the CONSORT Group in Montebello, Canada, January 2007, involving 26 participants, including clinical trialists, statisticians, epidemiologists, and biomedical editors. Checklist items were discussed for eligibility into the final checklist. The checklist was then revised to ensure that it reflected discussions held during and subsequent to the meeting. CONSORT for Abstracts recommends that abstracts relating to RCTs have a structured format. Items should include details of trial objectives; trial design (e.g., method of allocation, blinding/ masking); trial participants (i.e., description, numbers randomized, and number analyzed); interventions intended for each randomized group and their impact on primary efficacy outcomes and harms; trial conclusions; trial registration name and number; and source of funding. We recommend the checklist be used in conjunction with this explanatory document, which includes examples of good reporting, rationale, and evidence, when available, for the inclusion of each item.

\section{Conclusions}

CONSORT for Abstracts aims to improve reporting of abstracts of RCTs published in journal articles and conference proceedings. It will help authors of abstracts of these trials provide the detail and clarity needed by readers wishing to assess a trial's validity and the applicability of its results. 


\section{Introduction}

Well-written abstracts of conferences and journal articles reporting randomized controlled trials (RCTs) are important, because readers will often base their initial assessment of a trial on the information reported in an abstract. They may then use this information to decide whether or not to seek more knowledge about the trial, such as by reading the full report if available. In some geographic areas, the abstract of a RCT may be all that health professionals have easy access to, and health-care decisions may be made solely on information reported in it. Where the results of a trial are reported only as a conference abstract, this abstract may provide the only permanent information about a study and the only way that its results can be accessed by most readers [1]. Journal and conference abstracts should contain sufficient information about the trial to serve as an accurate record of its conduct and findings, providing optimal information about the trial within the space constraints of the abstract format. A properly constructed and well-written abstract should also help individuals to assess quickly the validity and applicability of the findings and, in the case of abstracts of journal articles, aid the retrieval of reports from electronic databases [2]. Conference abstracts, in particular, can provide valuable information for systematic reviewers about studies that are not otherwise published, the exclusion of which from the review might introduce bias [3].

\section{Incomplete and Inaccurate Reporting}

A number of studies have highlighted the need for improvements in the reporting of conference abstracts and the abstracts of journal articles presenting the results of RCTs [4]. There are concerns over the accuracy and quality of trial reports published in the proceedings of scientific meetings, including the lack of information about the trial and the robustness of the trial results, compared with results published in a journal article [5-9]. Research has also shown that trial information reported in conference abstracts may differ from that reported in subsequent full publications of the same study [10-13].

The abstract of a journal article has similar limitations to those of an abstract submitted to a scientific meeting. In particular, print space limitations constrain the detail that authors may include on the trial's methodology and results. A journal abstract should be an accurate reflection of what is included in the full journal article and should not include information that does not appear in the body of the paper. Studies comparing the accuracy of information reported in a journal abstract with that reported in the text of the full publication have found claims that are inconsistent with, or missing from, the body of the full article [14-18]. Conversely, omitting important contrary results from the abstract, such as those concerning side effects, could seriously mislead a reader's interpretation of the trial findings [19,20].

\section{Improving the Reporting of Randomized Trials in Journal and Conference Abstracts}

The CONSORT (Consolidated Standards of Reporting Trials) Statement, first published in 1996 [21] and updated in 2001 [22], provides recommendations for reporting RCTs in health-care journals. CONSORT has been endorsed by the World Association of Medical Editors (WAME), the Interna- tional Committee of Medical Journal Editors (ICMJE), and the Council of Science Editors (CSE). Currently, however, the CONSORT Statement provides limited guidance about preparing abstracts and, while it encourages the use of a structured format, this is not a formal requirement. The ICMJE Uniform Requirements [23] also provide only limited guidance on the format of abstracts for journal articles.

We believe that instructions to authors from journals and conference organizers should provide specific instructions about key elements of a trial that should be reported in an abstract. Indeed, a recent study examining the content of 35 journals' instructions to authors found that only $4 \%$ of all words were devoted to the content or format of the abstract [24]. Without a minimum amount of key information on a trial, it is difficult to assess the validity of its results or its applicability.

\section{Methods}

\section{CONSORT for Abstracts: Development of the Checklist}

In collaboration with others in the CONSORT Group, we have extended the current CONSORT Statement to develop a checklist of essential items that authors should consider when reporting the main (i.e., those reporting the pre-specified primary outcome) results of a RCT in any journal or conference abstract.

First, we established a steering committee (MC, SH, DM, PM, and EW). Second, we generated a list of items from existing quality assessment and reporting tools, including the CONSORT Statement [22] and other guidance for the structured reporting of journal abstracts and short reports [25-28]. Third, additional items were generated as part of an empirical study assessing the quality of trials reported in conference proceedings and journal abstracts [29].

We then used a modified Delphi consensus method [30] to select and reduce the number of possible checklist items. A total of 109 participants, who were known to have an interest in the reporting of RCTs, the structure of abstracts, or both were invited (by e-mail) to participate in a Web-based survey and rate the importance of 27 suggested checklist items. The response rate was $61 \%(n=63)$ for the first round of the Delphi survey. Respondents included journal editors (13\%), health-care professionals (22\%), methodologists (40\%), statisticians $(5 \%)$, trialists $(7 \%)$, and other individuals with expertise in the reporting of RCTs (13\%). During three rounds of the survey, participants were asked about their views on the relative importance of the possible checklist items. A more detailed discussion of the Delphi process is included in Text S1.

The results of the survey were presented at a one-day meeting (part of a three-day CONSORT Group meeting) in January 2007, in Montebello, Canada, attended by 26 participants, several of whom also participated in the Delphi survey. The meeting began with a review of the checklist items proposed as a result of the Delphi process. Participants then discussed in small groups whether proposed checklist items should be included, excluded, or modified in the final checklist. These small-group deliberations were further discussed during plenary sessions.

Following the meeting, the checklist was revised and circulated to the steering committee and meeting participants to ensure that it reflected the discussions. The steering 
committee also developed this explanation and elaboration document, which was circulated through several iterations among the authors.

\section{CONSORT for Abstracts Checklist: Explanation and Elaboration}

We developed this document using the template used to develop the CONSORT and STARD (Standards for Reporting Diagnostic Accuracy) explanatory articles [31,32]. Here each item (see Table 1) is stated, a recent example of good reporting of the item is provided, followed by an explanation that includes the rationale and scientific background and, where possible, discusses the evidence for the item as it relates to a trial reported in a journal or conference abstract.

\section{Checklist Items}

\section{TITLE}

Item: Identification of the study as randomized.

Example. "Effectiveness of a strategy to improve adherence to tuberculosis treatment in a resource poor setting: a cluster randomized trial" [33].

Explanation. The ability to identify a relevant report in an electronic database depends to a large extent on how it was indexed. Indexers may not classify a report as a RCT if the authors do not explicitly report this information [34]. To help ensure that a study is appropriately indexed and identified as a RCT, authors should state explicitly in the title that the participants were randomly assigned to their comparison groups.

\section{AUTHORS}

Item: Contact details for the corresponding author.

(This item is specific to conference abstracts)

Example. "Correspondence to: Dr Sally Hopewell, UK Cochrane Centre, Summertown Pavilion, Middle Way, Oxford OX2 7LG, UK. Tel: +44 1865 516300; Fax: +44 1865 516311; Email: shopewell@cochrane.co.uk."

Explanation. Adequate contact details for the corresponding author are particularly important for RCTs reported in conference proceedings. These abstracts may be the only lasting source of information for many trials, as only half of RCTs reported in conference proceedings are subsequently published in full [1]. Adequate contact information would enable readers to contact trialists for additional information or clarifications regarding reported data. Adequate contact details should include the telephone number, postal, and email address of the principal investigator and, if available, the trial Web site.

\section{TRIAL DESIGN}

Item: Description of the trial design.

Example. "A cluster randomized controlled trial..." [33].

Explanation. The design of the trial should be described, for example, parallel group, cluster randomized, crossover, factorial, superiority, equivalence or noninferiority, or some other combination of these designs. An important reason for identifying the design of the trial is to ensure appropriate indexing in electronic databases, thus ensuring greater ease of identification [34]. Alerting readers to the design of the trial also provides transparency as to the type of design used to conduct the trial and should reduce the likelihood of inadvertently misinterpreting data. For example, in a report of a cluster trial, readers might misinterpret a small sample size as the number of participants rather than the number of clusters, or vice versa [35].

\section{METHODS}

\section{Participants}

Item: Eligibility criteria for participants and the settings where the data were collected.

Example. “... conducted between June 2003 and January 2005, at 16 government district health centers in Senegal. Patients older than 15 years with newly diagnosed sputum smear-positive pulmonary TB were randomly assigned to the intervention or control group" [33].

Explanation. Every RCT addresses an issue relevant to a particular population or group with the condition of interest. Trialists may further restrict this sample by using eligibility criteria and by performing the trial in a particular setting (for example primary, secondary, or tertiary care). Participant eligibility criteria may relate to demographics, clinical diagnosis, and comorbid conditions. A clear description of the trial participants and setting in which they were studied is needed so that readers may assess the external validity (generalisability) of the trial and determine its applicability to their own setting.

\section{Interventions}

Item: Interventions intended for each group.

Example. "Patients were randomized to receive either 100 mg hydrocortisone or matching placebo as follows: the first dose in the evening of the operative day, then 1 dose every 8 hours during the next 3 days. In addition, all patients received oral metoprolol (50-150 mg/d) titrated to heart rate" [36].

Explanation. The essential features of the experimental and comparison interventions should be described. Authors should report details about the interventions, e.g., dose, route of administration, duration of administration, surgical procedure, or manufacturer of inserted device.

\section{Objective}

Item: Specific objective or hypothesis.

Example. "To compare the effectiveness of an early switch to oral antibiotics with the standard 7 day course of intravenous antibiotics in severe community acquired pneumonia" [37].

Explanation. The abstract should provide a clear statement of the specific objective or hypothesis addressed in the trial. If more than one objective is addressed, the main objective (i.e., based on the prespecified primary outcome) should be indicated and only key secondary objectives stated [26].

\section{Outcome}

Item: Clearly defined primary outcome for this report.

Example. "Main outcome measure: all-cause mortality at 180 days" [38].

Explanation. RCTs assess outcomes for which the interventions are being compared. Most trials have several outcomes, some of which are deemed more important than others. Such rankings are typically reported as primary and secondary outcomes. There is evidence of selective reporting with significant or favourable outcomes being more likely to be published than nonsignificant outcomes [39-41]. 
Table 1. Items to Include when Reporting a Randomized Trial in a Journal or Conference Abstract

\begin{tabular}{|c|c|}
\hline Item & Description \\
\hline Title & Identification of the study as randomized \\
\hline Authors* & Contact details for the corresponding author \\
\hline Trial design & Description of the trial design (e.g. parallel, cluster, non-inferiority) \\
\hline \multicolumn{2}{|r|}{ 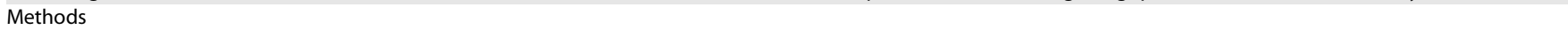 } \\
\hline Participants & $\begin{array}{l}\text { Eligibility criteria for participants and the settings where the data were } \\
\text { collected }\end{array}$ \\
\hline Interventions & Interventions intended for each group \\
\hline Objective & Specific objective or hypothesis \\
\hline Outcome & Clearly defined primary outcome for this report \\
\hline Randomization & How participants were allocated to interventions \\
\hline Blinding (masking) & $\begin{array}{l}\text { Whether or not participants, care givers, and those assessing the outcomes } \\
\text { were blinded to group assignment }\end{array}$ \\
\hline \multicolumn{2}{|r|}{ 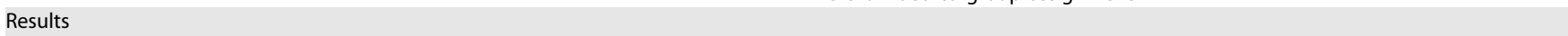 } \\
\hline Numbers randomized & Number of participants randomized to each group \\
\hline Recruitment & Trial status \\
\hline Numbers analysed & Number of participants analysed in each group \\
\hline Outcome & $\begin{array}{l}\text { For the primary outcome, a result for each group and the estimated effect size } \\
\text { and its precision }\end{array}$ \\
\hline Harms & Important adverse events or side effects \\
\hline Conclusions & General interpretation of the results \\
\hline Trial registration & Registration number and name of trial register \\
\hline Funding & Source of funding \\
\hline
\end{tabular}

*This item is specific to conference abstracts.

doi:10.1371/journal.pmed.0050020.t001

Authors should explicitly state the primary outcome for the trial and when it was assessed (e.g., the time frame over which it was measured). The primary outcome is the prespecified outcome considered of greatest importance and is usually the one used in the sample size calculation [22]. In some instances a publication may report an outcome different from the primary outcome. For example, conference abstracts are more likely to report interim analyses than are full publications $[8,10]$, or to present different results for a single trial in a series of abstracts. If the abstract focuses on a secondary outcome of a trial, the abstract should identify both this outcome and the primary outcome of the trial.

\section{Randomization}

Item: How participants were allocated to interventions.

Example. "Randomization was computer-generated, with allocation concealment by opaque sequentially numbered sealed envelopes" [42].

Explanation. It is important to conceal the allocation sequence from those assigning participants to the intervention groups. Allocation concealment prevents investigators from influencing which participants are assigned to a given intervention group (i.e., selection bias). Evidence shows that reports of trials reporting inadequate allocation concealment are associated with exaggerated treatment effects $[43,44]$. Research suggests that adequate allocation concealment is more important in preventing selection bias than are other components of the randomization process, such as the sequence generation (e.g., use of computer or random number table) [45].

Authors should clearly describe the method for assigning participants to interventions. Examples of approaches used to ensure adequate concealment include: centralised (e.g., allocation by a central office) or pharmacy-controlled randomization; sequentially numbered identical containers that are administered serially to participants; on-site computer system combined with allocations kept in a locked, unreadable computer file that investigators can access only after the characteristics of an enrolled participant are entered; and sequentially numbered, opaque sealed envelopes [46].

The method of allocation concealment is generally poorly reported in conference abstracts and in abstracts of journal articles [7,47-49]. For example, in a review of 494 abstracts presented at an oncology conference in 1992 and 2002, only nine $(2 \%)$ abstracts reported the method of allocation concealment. This information was missing from the remaining 485 conference abstracts, with no improvements seen over the ten-year period [7].

\section{Blinding (Masking) \\ Item: Whether or not participants, caregivers, and those assessing the outcomes were blinded to group assignment.}

Example. "Children, parents, and the research assistants were blinded to group assignment" [50].

Explanation. Blinding refers to the practice of keeping the trial participants, care providers, data collectors, and sometimes those analysing the data, unaware of which intervention is being administered to which participant, so that they will not be influenced by that knowledge. The term masking is sometimes used instead of blinding [51,52] and might be preferable when reporting studies involving eyes and vision. It is important that authors describe whether or not participants, those administering the intervention (usually health-care providers), and those assessing the outcome (the data collectors and analysts) were blinded to the group 
allocation. Authors should avoid using terms such as "single" or "double" blind as such terms are not well-understood [53].

Information on the method of blinding is poorly reported in conference and journal abstracts $[7,8,47-49]$. Such reporting is valuable as blinding may be important in protecting against bias [51]. Studies have shown that if investigators are aware of the treatment, their attitudes for or against an intervention can directly affect whether or not they include, or treat, participants in a trial [45]. Furthermore, there is evidence that participants who are aware of their assignment status are more likely to report symptoms, leading to biased results [51]. Perhaps most importantly, if outcome assessors are not blinded to the intervention they are more likely to report favourable outcomes for the intervention which they believe is better [54]. However, unlike allocation concealment, blinding of the participants, health-care providers, and outcome assessors may not always be appropriate or possible, such as in many surgical trials. In this case, authors should report if any form of blinding (such as blinding of data analysts) was used.

\section{RESULTS}

Numbers Randomized

Item: Number of participants randomized to each group.

Example. "Children $(n=633)$ aged $1-3$ randomly allocated to receive fortified milk $(n=316)$ or control milk $(n=317)$ " [55].

Explanation. The number of participants randomized to each intervention group is an essential element of the results of a trial. This number defines the sample size, and readers can use it to assess whether all randomized participants were included in the data analysis. Again, this may be particularly important for conference abstracts reporting interim analyses, if a trial is still open to participant accrual or follow-up $[8,10]$. Here authors should report the period of recruitment on which the data are based.

\section{Recruitment}

Item: Trial status.

Example. "An interim analysis was performed because of slow accrual" [56].

Explanation. Authors should describe the status of the trial and whether it is still ongoing, closed to recruitment, or closed to follow-up. This information is particularly important for conference abstracts, which are more likely than full articles to report interim analyses [10].

If the trial has stopped earlier than planned it is important to say why. Possible reasons for early termination include: slow accrual rates, poor data quality, poor adherence, resource deficiencies, unacceptable harms or large benefits, or emerging information that makes the trial irrelevant, unnecessary, or unethical. If a trial stops early for apparent benefit, the estimates of treatment effect are more likely to be biased and prone to exaggeration $[57,58]$.

\section{Numbers Analysed}

Item: Number of participants analysed in each group.

Example. "... 300 were included in the analysis of the primary outcome (100 in the acetaminophen group, 100 in the ibuprofen group, and 100 in the codeine group)" [50].

Explanation. Authors should report the number of participants included in the analysis for each intervention group. These data permit an assessment of whether participants were analysed according to their original group assignment, which is important, because failure to include all participants in the analysis may bias the results of the trial [22].

Several studies have reported deficiencies in journal and conference abstracts in reporting the number of participants included in the analysis $[6-8,13,48,59]$. In a review of RCTs in acute brain injury reported in journal abstracts, only $43 \%$ reported the number of participants included in the analysis [48]. In another evaluation of trials reported in abstracts for an oncology conference, only $40 \%$ reported the number of participants analysed, and only $6 \%$ indicated intention to treat analysis [8].

\section{Outcome}

Item: For the primary outcome, a result for each group and the estimated effect size and its precision.

Example. "Treatment was successful for $682(88 \%)$ of 778 patients recruited in the intervention group, and for 563 (76\%) of 744 patients recruited in the control group (adjusted risk ratio [RR], 1.18; $95 \%$ confidence interval [CI], 1.03-1.34)" [33].

Explanation. For the primary outcome, authors should report trial results as a summary of the outcome in each group (e.g., the number of participants with or without the event, or the mean and standard deviation of measurements), together with the contrast between groups known as the effect size. For binary outcomes, the effect size could be the relative risk, relative risk reduction, odds ratio, or risk difference. For survival time data, the measurement could be the hazard ratio or difference in median survival time. For continuous data, the effect measure is usually the difference in means. Authors should present confidence intervals for the contrast between groups and as a measure of the precision (uncertainty) of the estimate of the effect [22]. For abstracts not reporting the "primary" outcome of the trial (e.g., abstracts focusing on safety data or economic impacts), the secondary nature of the outcomes should be indicated, and, where possible, sufficient details of the primary outcome should be included to allow other findings to be taken in the proper context.

Several studies have observed deficiencies in the reporting of statistical results in journal abstracts [57,60-62]. For example, Pocock and colleagues [57] found that journal abstracts of RCTs tended to overemphasize statistically significant outcomes compared to the full journal article, leading to problems in interpretation of the results. Poor reporting of results is also a problem for trials presented in conference abstracts [7,8,59]. A study of 494 reports of RCTs in oncology found that only $26 \%$ of conference abstracts reported the size of the effect and significance of the result [7].

\section{Harms}

Item: Important adverse events or side effects.

Example. "Adverse events were more common with topiramate vs placebo, respectively, including paresthesia $(50.8 \%$ vs $10.6 \%)$, taste perversion $(23.0 \%$ vs $4.8 \%)$, anorexia $(19.7 \%$ vs $6.9 \%)$, and difficulty with concentration $(14.8 \%$ vs $3.2 \%)$ " [63].

Explanation. Most interventions have unintended and 
often undesirable effects as well as intended and beneficial effects. In order to make rational and balanced decisions, readers need information about the relative benefits and harms of an intervention. Authors should describe any important adverse (or unexpected) effects of an intervention in the abstract. If no important adverse events have occurred, the authors should state this explicitly [20].

Explicit reference to the reporting of harms in the title or abstract is also important for appropriate database indexing and information retrieval. Derry and colleagues [64] found that only 66 of 107 RCTs that reported data on adverse events in the full publication mentioned harms in the title or abstract; thus, harms could not have been identified for many of the articles in a search of titles and abstracts in an electronic bibliographic database.

Harms are also poorly reported in conference abstracts. A recent examination of over 800 ophthalmology conference abstracts reporting trials found that the majority $(71 \%)$ did not report harms related to the treatment intervention, and harms were reported as a primary outcome measure in only $6 \%$ of abstracts [9].

\section{CONCLUSIONS}

Item: General interpretation of the results.

Example. "Multivitamin supplementation reduced the incidence of low birth weight and small-for-gestational-age births but had no significant effects on prematurity or fetal death" [65].

Explanation. The conclusions of the trial, consistent with the results reported in the abstract, should be clearly stated along with their clinical application (avoiding over-generalisation). Authors should balance the benefits and harms in their conclusions. Where applicable, authors should also note whether additional studies are required before the results are used in clinical settings [26].

\section{TRIAL REGISTRATION}

Item: Registration number and name of trial register.

Example. "Trial Registry: www.clinicaltrials.gov; Identifier: NCT00412009" [33].

Explanation. Nonpublication of entire trials and selective reporting of outcomes within trials has been well-documented $[39,41,66]$. Covert redundant publication can also cause problems in systematic reviews when results from the same trial are inadvertently included more than once [67]. To minimize or avoid these problems there have been many calls for trial registration [68]. Due to more recent serious problems of withholding data [69] there has been a renewed effort to register RCTs. By registering a RCT, authors typically report a minimal set of information and obtain a unique trial registration number.

In September 2004 the International Committee of Medical Journal Editors (ICMJE) indicated a change in their policy for publishing RCTs, saying that they would consider trials for publication only if they had been registered before the enrolment of the first patient (as of 1 July 2005) [70]. This position has resulted in a dramatic increase in the number of trials being registered [71].

In an abstract reporting a trial, authors should provide details of the trial registration number and name of trial register. Registration information will be particularly important for abstracts reported in conference meetings, as not all of them are subsequently published [1]. Such trial registration provides readers with a way to obtain more information about the trial and its results. Registration information will also help to link abstracts with subsequent full publications (or multiple abstracts from the same trial) and thus reduce the risk of inadvertent double-counting in systematic reviews.

\section{FUNDING}

Item: Source of funding.

Example. "Funded by The Breast Cancer Research Foundation" [72].

Explanation. Authors should report the source of funding for the trial as this is important information for readers assessing a trial. A recent systematic review showed that studies funded by the pharmaceutical industry had four times (odds ratio 4.05; 95\% confidence interval 2.98-5.51) the odds of having outcomes favouring the sponsor than studies funded by other sources [73]. Similarly, authors should report any other sources of support, such as in the preparation of the abstract, presentation, or manuscript [74].

\section{Discussion}

CONSORT for Abstracts strongly recommends the use of structured abstracts for reporting RCTs [75]; the full CONSORT Statement also supports their use [22]. Since 1987 when the Ad Hoc Working Group for Critical Appraisal of the Medical Literature [25-27] first published recommendations for the adoption of structured abstracts, many journals have promoted their use, and many different formats for structured abstracts now exist. We recognise that journals may have developed their own set of headings for abstracts $[76,77]$. It is not the intention of this reporting guide to suggest changes to these headings but to recommend what information should be reported within them when describing a RCT.

It is important to note that, because of the space limitations of an abstract, it will only ever be possible to provide limited information about a trial report. CONSORT for Abstracts sets out to recommend what information should be reported within these constraints when describing a RCT. Readers of abstracts should always try to obtain more information about a trial and its results, either by accessing the full publication or, in the case of unpublished conference abstracts [1], by contacting the authors for more information.

With the aim of greatly improving access to information about clinical trials and their results, the World Health Organization (WHO) recently established an International Clinical Trials Registry Platform. Their goal is to produce a single minimum standard for information that trialists should disclose before the trial begins [78,79]. Moreover, as registration of the trial methods has become more common, several forces have begun to advocate for the disclosure of trial results in specially designed repositories linked to trial registers. In June 2007, endorsing the WHO's International Clinical Trials Registry Platform, the ICMJE published an editorial recommending a standard abstract format for reporting results. The ICMJE suggested that CONSORT for Abstracts may be one such option [80]. At present, there is no formal consensus on international norms and standards for results reporting. The WHO International Clinical Trials Registry Platform has therefore established a Study Group on 
the Reporting of Findings of Clinical Trials to advise the WHO Registry Platform on matters related to the reporting of the findings of clinical trials. Full transparency and accountability require that all results of all trials are made available to the public in a timely manner.

Like the CONSORT Statement, CONSORT for Abstracts has been developed primarily for reporting the main results of parallel group RCTs (i.e., those relating to the prespecified primary outcome). There may well be instances where different types of trial information, such as composite outcomes, or different designs, such as cluster trials or noninferiority and equivalence trials, will require additional information not covered in this explanation and elaboration document. Possible additional abstract extensions may be warranted, as has been done for the CONSORT Statement for full reports $[35,81]$.

The length of an abstract reporting a RCT using the CONSORT for Abstracts checklist is difficult to estimate. In developing the checklist 250 to 300 words were found to be sufficient to address all of the items in the checklist. Worked examples of using the CONSORT for Abstracts checklist are available on the CONSORT website at http://www. consort-statement.org/. In the past, MEDLINE has truncated journal abstracts at 250 words [82]. This has resulted in many journals setting word limits for abstracts in their journals at 250 words. However, since 2000 the National Library of Medicine increased the word limit for an abstract appearing in MEDLINE to 10,000 characters, which equates to over 1,000 words. While most abstract reports will not require anywhere near 1,000 words, such a word length will be sufficient to report even the most complex of trials in abstract form [82].

Clear, transparent, and accurate reporting of research is important because it enables readers to understand what was done and hence to evaluate the reliability and relevance of the findings. This extension of the CONSORT Statement aims to improve the reporting of RCTs in both the abstracts of journal articles and conference proceedings [83]. When using the CONSORT for Abstracts checklist we encourage authors to use it in conjunction with this explanation and elaboration document. We encourage journals and conference organisers to endorse the use of CONSORT for Abstracts by modifying their "Instructions to Authors" and drawing their readers' attention to this reporting guidance, perhaps through an editorial or by including a link to the checklist on the conference website. The most important benefit will be to enable readers to use abstracts more effectively and to assess the validity of the research more precisely. When key aspects of study methods are omitted, reader assessments are less certain, and might well take longer to make.

\section{Supporting Information}

Text S1. Results of the Delphi Consensus Survey

Found at doi:10.1371/journal.pmed.0050020.sd001 (69 KB RTF).

\section{Acknowledgments}

We are grateful to everyone who contributed to the development of CONSORT for Abstracts and to the Delphi survey. We are also grateful to those who participated in the meeting of the CONSORT Group in January 2007 and commented on drafts of the manuscript: Virginia Barbour, PLoS Medicine, United Kingdom; Jesse Berlin,
Johnson \& Johnson Pharmaceutical Research and Development, United States; Isabelle Boutron, University Paris 7 Denis Diderot, Assistance Publique des Hôpitaux de Paris, INSERM, France; P.J. Devereaux, McMaster University, Canada; Kay Dickersin, Johns Hopkins Bloomberg School of Public Health, United States; Diana Elbourne, London School of Hygiene \& Tropical Medicine, United Kingdom; Susan Ellenberg, University of Pennsylvania School of Medicine, United States; Val Gebski, University of Sydney, Australia; Steven Goodman, Journal of the Society for Clinical Trials, United States; Peter C. Gøtzsche, Nordic Cochrane Centre, Denmark; Trish Groves, $B M J$, United Kingdom, Steven Grunberg, American Society of Clinical Oncology, United States; Brian Haynes, ACP Journal Club, Canada; Astrid James, The Lancet, United Kingdom; Peter Juhn, Johnson \& Johnson, United States; Don Minckler, University of California Irvine, United States; Victor M. Montori, Knowledge and Encounter Research Unit, Mayo Clinic College of Medicine, United States; Cynthia Mulrow, Annals of Internal Medicine, United States; Stuart Pocock, London School of Hygiene \& Tropical Medicine, United Kingdom; Drummond Rennie, JAMA, United States; David Schriger, Annals of Emergency Medicine, United States; Iveta Simera, EQUATOR Network, United Kingdom.

Author contributions. SH, MC, DM, EW, and PM were involved in the design, implementation, analysis of the study, and in writing and commenting on drafts on the final manuscript. DGA and KFS were involved in the analysis of the study and commenting on drafts on the final manuscript.

\section{References}

1. Scherer RW, Langenberg P, von Elm E (2007) Full publication of results initially presented in abstracts. Cochrane Database of Systematic Reviews, Art. No.: MR000005. doi:10.1002/14651858.MR000005.pub3. Available: http:/l www.mrw.interscience.wiley.com/cochrane/clsysrev/articles/MR000005/ frame.html. Accessed 1 May 2007.

2. Harbourt AM, Knecht LS, Humphreys BL (1995) Structured abstracts in MEDLINE, 1989-1991. Bull Med Libr Assoc 83: 190-195.

3. Hopewell S, McDonald S, Clarke M, Egger M (2007) Grey literature in metaanalyses of randomized trials of health care interventions. Cochrane Database of Systematic Reviews, Art. No.: MR000010. doi:10.1002/14651858. MR000010.pub3. Available: http://www.mrw.interscience.wiley.com/ cochrane/clsysrev/articles/MR000010/frame.html. Accessed 1 May 2007.

4. Hopewell S, Eisinga A, Clarke M (2007) Better reporting of randomized trials in biomedical journal and conference abstracts. J Info Sci doi:10.1177/ 0165551507080415 .

5. Chalmers I, Adams M, Dickersin K, Hetherington J, Tarnow-Mordi W, et al. (1990) A cohort study of summary reports of controlled trials. JAMA 263: 1401-1405.

6. Herbison P (2005) The reporting quality of abstracts of randomised controlled trials submitted to the ICS meeting in Heidelberg. Neurourol Urodyn 24: 21-24.

7. Hopewell S, Clarke M (2005) Abstracts presented at the American Society of Clinical Oncology conference: how completely are trials reported? Clin Trials 2: 265-268.

8. Krzyzanowska MK, Pintilie M, Tannock IF (2003) Factors associated with failure to publish large randomized trials presented at an oncology meeting. JAMA 290: 495-501.

9. Scherer R (2006) Are harms reported in abstracts of trial results from conference proceedings? XIV Cochrane Colloquium, 23-26 October, Dublin, Ireland: 63.

10. Hopewell S, Clarke M, Askie L (2006) Reporting of trials presented in conference abstracts needs to be improved. J Clin Epidemiol 59:: 681-684.

11. Toma M, McAlister FA, Bialy L, Adams D, Vandermeer B, et al. (2006) Transition from meeting abstract to full-length journal article for randomized controlled trials. JAMA 295: 1281-1287.

12. Dundar Y, Dodd S, Dickson R, Walley T, Haycox A, et al. (2006) Comparison of conference abstracts and presentations with full-text articles in the health technology assessments of rapidly evolving technologies. Health Technol Assess 10: 1-145.

13. Chokkalingam A, Scherer R, Dickersin K (1998) Agreement of data abstracts compared to full publications. Control Clin Trials 19: 61S-62S.

14. Estrada CA, Bloch RM, Antonacci D, Basnight LL, Patel SR, et al. (2000) Reporting and concordance of methodologic criteria between abstracts and articles in diagnostic test studies. J Gen Intern Med 15: 183-187.

15. Froom P, Froom J (1993) Deficiencies in structured medical abstracts. J Clin Epidemiol 46: 591-594.

16. Harris AH, Standard S, Brunning JL, Casey SL, Golderg JH, et al. (2002) The accuracy of abstracts in psychology journals. J Psychol 136: 141-148.

17. Pitkin RM, Branagan MA, Burmeister LF (1999) Accuracy of data in abstracts of published research articles. JAMA 281: 1110-1111.

18. Ward LG, Kendrach MG, Price SO (2004) Accuracy of abstracts for original research articles in pharmacy journals. Ann Pharmacother 38: 1173-1177.

19. Ioannidis JP, Lau J (2001) Completeness of safety reporting in randomized trials: an evaluation of 7 medical areas. JAMA 285: 437-443.

20. Ioannidis JP, Evans SJ, Gøtzsche PC, O’Neill RT, Altman DG, et al. (2004) 
Better reporting of harms in randomized trials: an extension of the CONSORT statement. Ann Intern Med 141: 781-788.

21. Begg C, Cho M, Eastwood S, Horton R, Moher D, et al. (1996) Improving the quality of reporting of randomized controlled trials. The CONSORT statement. JAMA 276: 637-639.

22. Moher D, Schulz KF, Altman DG, Lepage L (2001) The CONSORT statement: revised recommendations for improving the quality of reports of parallel-group randomised trials. Lancet 357: 1191-1194.

23. International Committee of Medical Journal Editors (2006) Uniform requirements for manuscripts submitted to biomedical journals: writing and editing for biomedical publication. [Updated February 2006.] Available: http://www.icmje.org. Accessed 1 December 2006.

24. Schriger DL, Arora S, Altman DG (2006) The content of medical journal Instructions for authors. Ann Emerg Med 48: 743-749.

25. Ad Hoc Working Group for Critical Appraisal of the Medical Literature (1987) A proposal for more informative abstracts of clinical articles. Ann Intern Med 106: 598-604.

26. Haynes RB, Mulrow CD, Huth EJ, Altman DG, Gardner MJ (1990) More informative abstracts revisited. Ann Intern Med 113: 69-76.

27. Haynes RB, Mulrow CD, Huth EJ, Altman DG, Gardner MJ (1996) More informative abstracts revisited. Cleft Palate-Craniofac J 33: 1-9.

28. Deeks JJ, Altman DG (1998) Inadequate reporting of controlled trials as short reports. Lancet 318: 193-194.

29. Hopewell S (2004) Impact of grey literature on systematic reviews of randomized trials [PhD dissertation]. Oxford (UK): Wolfson College, University of Oxford.

30. Hasson F, Keeney S, McKenna H (2000) Research guidelines for the Delphi survey method. J Adv Nurs 32: 1008-1015.

31. Altman DG, Schulz KF, Moher D, Egger M, Davidoff F, et al. (2001) The revised CONSORT statement for reporting randomized trials: explanation and elaboration. Ann Intern Med 134: 663-694.

32. Bossuyt PM, Reitsma JB, Bruns DE, Gatsonis CA, Glasziou PP, et al. (2003) The STARD statement for reporting studies of diagnostic accuracy: explanation and elaboration. Ann Intern Med 138: W1-12.

33. Thiam S, LeFevre AM, Hane F, Ndiaye A, Ba F, et al. (2007) Effectiveness of a strategy to improve adherence to tuberculosis treatment in a resourcepoor setting: a cluster randomized controlled trial. JAMA 297: 380-386.

34. Dickersin K, Manheimer E, Wieland S, Robinson KA, Lefebvre C, et al (2002) Development of the Cochrane Collaboration's CENTRAL register of controlled clinical trials. Eval Health Prof 25: 38-64.

35. Campbell MK, Elbourne DR, Altman DG; CONSORT group (2004) CONSORT statement: extension to cluster randomised trials. BMJ 328 702-708.

36. Halonen J, Halonen P, Jarvinen O, Taskinen P, Auvinen T, et al. (2007) Corticosteroids for the prevention of atrial fibrillation after cardiac surgery: a randomized controlled trial. JAMA 297: 1562-1567.

37. Oosterheert JJ, Bonten MJ, Schneider MM, Buskens E, Lammers JW, et al. (2006) Effectiveness of early switch from intravenous to oral antibiotics in severe community acquired pneumonia: multicentre randomised trial. BMJ 33: 1193.

38. Mebazaa A, Nieminen MS, Packer M, Cohen-Solal A, Kleber FX, et al. (2007) Levosimendan vs dobutamine for patients with acute decompensated heart failure: the SURVIVE randomized trial. JAMA 297: 1883-1891.

39. Chan AW, Hrobjartsson A, Haahr MT, Gøtzsche PC, Altman DG (2004A) Empirical evidence for selective reporting of outcomes in randomized trials: comparison of protocols to published articles. JAMA 291: 24572465

40. Chan AW, Altman DG (2004B) Identifying outcome reporting bias in randomised trials on PubMed: review of publications and survey of authors. BMJ 330: 753 .

41. Williamson PR, Gamble C (2005) Identification and impact of outcome selection bias in meta-analysis. Stat Med 24: 1547-1561.

42. Johnson NP, Farquhar CM, Hadden WE, Suckling J, Yu Y, et al. (2004) The FLUSH trial: flushing with lipiodol for unexplained (and endometriosisrelated) subfertility by hysterosalpingography: a randomized trial. Hum Reprod 19: 2043-2051.

43. Gluud LL (2006) Bias in clinical intervention research. Am J Epidemiol 163 493-501.

44. Pildal J, Hrobjartsson A, Jorgensen K, Hilden J, Altman D, et al. (2007) Impact of allocation concealment on conclusions drawn from metaanalyses of randomized trials. Int J Epidemiol 36: 847-857.

45. Juni P, Altman DG, Egger M (2001) Systematic reviews in health care: assessing the quality of controlled clinical trials. BMJ 323: 42-46.

46. Schulz KF, Grimes DA (2002) Allocation concealment in randomised trials: defending against deciphering. Lancet 359: 614-618.

47. Scherer RW, Crawley B (1998) Reporting of randomized clinical trial descriptors and use of structured abstracts. JAMA 280: 269-272.

48. Burns KEA, Adhikari NKJ, Kho M, Meade MO, Patel RV, et al. (2005) Abstract reporting in randomized clinical trials of acute lung injury: an audit and assessment of a quality of reporting score. Crit Care Med 33: $1937-1945$.

49. Taddio A, Pain T, Fassos FF, Boon H, Ilersich AL, et al. (1994) Quality of nonstructured and structured abstracts of original research articles in the British Medical Journal, the Canadian Medical Association Journal and the Journal of the American Medical Association. CMAJ 150: 1611-1618.
50. Clark E, Plint AC, Correll R, Gaboury I, Passi B (2007) A randomized, controlled trial of acetaminophen, ibuprofen, and codeine for acute pain relief in children with musculoskeletal trauma. Pediatrics 119: 460-467.

51. Schulz KF, Grimes DA (2006) The Lancet handbook of essential concepts in clinical research. London: Elsevier.

52. Schulz KF, Altman DG, Moher D (2007) Blinding is better than masking. BMJ 334: 918.

53. Devereaux PJ, Manns BJ, Ghali WA, Quan H, Lacchetti C, et al. (2001) Physician interpretations and textbook definitions of blinding terminology in randomized controlled trials JAMA 285: 2000-2003.

54. Poolman RW, Struijs PA, Krips R, Sierevelt IN, Marti RK, et al. (2007) Reporting of outcomes in orthopaedic randomized trials: does blinding of outcome assessors matter? J Bone Joint Surg 89-A: 550-558.

55. Sazawal S, Dhingra U, Dhingra P, Hiremath G, Kumar J, et al. (2007) Effects of fortified milk on morbidity in young children in north India: community based, randomised, double masked placebo controlled trial. BMJ 334: 140 .

56. Kim KB, Legha SS, Gonzalez R, Anderson C, Papadopoulos NE, et al. (2006) A phase III randomized trial of adjuvant biochemotherapy (BC) versus interferon- $\alpha$-2b (IFN) in patients (pts) with high risk for melanoma recurrence. J Clin Oncol, ASCO Annual Meeting Proceedings Part I. Vol 24: 8003

57. Pocock SJ, Hughes MD, Lee RJ (1987) Statistical problems in the reporting of clinical trials. N Engl J Med 317: 426-432.

58. Montori VM, Devereaux PJ, Adhikari NK, Burns KE, Eggert CH, et al. (2005) Randomized trials stopped early for benefit: a systematic review. JAMA 294: 2203-2209.

59. Bhandari M, Devereaux PJ, Guyatt GH, Cook DJ, Swiontkowski MF, et al. (2002) An observational study of orthopaedic abstracts and subsequent fulltext publications. J Bone Joint Surg 84-A: 615-621.

60. Dryver E, Hux JE (2002) Reporting of numerical and statistical differences in abstracts: improving but not optimal. J Gen Intern Med 17: 203-206.

61. Gøtzsche PC (2006) Believability of relative risks and odds ratios in abstracts: cross sectional study. BMJ 333: 231-234.

62. Schwartz LM, Woloshin S, Dvorin EL, Welch HG (2006) Ratio measures in leading medical journals: structured review of accessibility of underlying absolute risks. BMJ 333: 1248-1250.

63. Johnson BA, Rosenthal N, Capece JA, Wiegand F, Mao L, et al. (2007) Topiramate for treating alcohol dependence: a randomized controlled trial. JAMA 298: 1641-1651.

64. Derry S, Kong Loke Y, Aronson JK (2001) Incomplete evidence: the inadequacy of databases in tracing published adverse drug reactions in clinical trials. BMC Med Res Methodol 1: 7 .

65. Fawzi WW, Msamanga GI, Urassa W, Hertzmark E, Petraro P, et al. (2007) Vitamins and perinatal outcomes among HIV-negative women in Tanzania. N Engl J Med 356: 1423-1431.

66. Dickersin K (1997) How important is publication bias? A synthesis of available data. AIDS Educ Prev 9: 15-21

67. Tramer MR, Reynolds DJ, Moore RA, McQuay HJ (1997) Impact of covert duplicate publication on meta-analysis: a case study. BMJ 315: 635-640.

68. Simes RJ (1986) Publication bias: the case for an international registry of clinical trials. J Clin Oncol 4: 1529-1541.

69. Whittington CJ, Kendall T, Fonagy P, Cottrell D, Cotgrove A, et al. (2004) Selective serotonin reuptake inhibitors in childhood depression: systematic review of published versus unpublished data. Lancet 363: 1341-1345.

70. De Angelis CD, Drazen JM, Frizelle FA, Haug C, Hoey J, et al. (2005) Is this clinical trial fully registered? A statement from the International Committee of Medical Journal Editors. Lancet 365: 1827-1829.

71. Zarin DA, Ide NC, Tse T, Harlan WR, West JC, et al. (2007) Issues in the registration of clinical trials. JAMA 297: 2112-2120.

72. Zellars RC, Frassica D, Stearns V, Fetting JH, Armstrong DK, et al. (2006) Partial breast irradiation (PBI) concurrent with adjuvant dose-dense doxorubicin and dyclophosphamide (ddAC) chemotherapy in early-stage breast cancer: Preliminary safety results from a feasibility trial. J Clin Oncol, ASCO Annual Meeting Proceedings Part I. Vol 24, No. 18S (June 20 Supplement), 2006: 10675

73. Lexchin J, Bero LA, Djulbegovic B, Clark O (2003) Pharmaceutical industry sponsorship and research outcome and quality: systematic review. BMJ 326: $1167-1170$.

74. Bero L, Oostvogel F, Bacchetti P, Lee K (2007) Factors associated with findings of published trials of drug-drug comparisons: why some statins appear more efficacious than others. PLoS Med 4: e184. doi: 10.1371/ journal.pmed.0040184

75. Hartley J (2004) Current findings from research on structured abstracts. J Med Libr Assoc 92: 368-371.

76. Guimaraes CA (2006) Structured abstracts: narrative review. Acta Cir Bras 21: 263-268.

77. Sollaci LB, Pereira MG (2004) The introduction, methods, results, and discussion (IMRAD) structure: a fifty-year survey. J Med Libr Assoc 92: 364367.

78. Gulmezoglu AM, Pang T, Horton R, Dickersin K (2005) WHO facilitates international collaboration in setting standards for clinical trial registration. Lancet 365: 1829-1831.

79. World Health Organisation (2007) International Clinical Trials Registry Platform. http://www.who.int/ictrp/en/. Accessed 12 June 2007. 
80. Laine C, Horton R, Deangelis CD, Drazen JM, Frizelle FA, et al. (2007) Clinical trial registration: looking back and moving ahead. BMJ 334: 1177 1178

81. Piaggio G, Elbourne DR, Altman DG, Pocock SJ, Evans SJW (2006) Reporting of noninferiority and equivalence randomized trials: an extension of the CONSORT statement. JAMA 295: 1152-1160.
82. National Library of Medicine (2007) MEDLINE / PubMed data element (field) descriptions. Available: http://www.nlm.nih.gov/bsd/mms/ medlineelements.html. Accessed 16 April 2007.

83. Hill CL, Buchbinder R, Osborne R (2007) Quality of reporting of randomized clinical trials in abstracts of the 2005 Annual Meeting of the American College of Rheumatology. J Rheumatol 34: 2476-2480. 